\title{
Expectations, Practices, And Preferences Of College Students: A Cross-Cultural Perspective Of CIS-Born And Israeli-Born Students In Israel
}

\author{
Nitza Davidovitch, Ariel University Center of Samaria, Israel \\ Lobova Elena, Ural State Pedagogical University, Russia \\ Pryamikova Elena, Ural State Pedagogical University, Russia \\ Semenova Tatiana, Ural State Pedagogical University, Russia \\ Pechenkina Tatiana, Ural State Pedagogical University, Russia \\ Yachmeneva Maria, Ural State Pedagogical University, Russia
}

\begin{abstract}
Processes of globalization are permeating the world of higher education and escalating to a previously unprecedented degree, and institutions of higher education previously known for their cultural homogeneity are becoming increasingly heterogeneous. Consequently, cross-cultural study of higher education is evolving from a discipline investigating a relatively marginal phenomenon to one examining a rapidly accelerating process shifting from the margins to the center. Today some claim that cultural differences between students are an essential factor affecting their study expectations, practices, and preferences. This study seeks to examine differences in learning styles, expectations, and study practices of Israeli students versus students in the Commonwealth of Independent States (CIS).

The research population consisted of 1,122 students, 554 studying in Israeli institutions of higher education and 568 in the CIS.

The research tool was developed specifically for this study and it consisted of 44 items related to four main spheres: 1) students' personal and academic background characteristics, 2) perception of the academic world and of the opportunities afforded by higher education, 3) evaluation of the study environment, and 4) faculty/student responsibility for the study process.

Research results indicate intercultural differences on almost all dimensions examined - personal and academic characteristics, perception of opportunities offered by academic studies as manifested in perception of crucial factors for selecting schools, factors arousing academic interest, crucial factors producing competent lecturers, requirements for receiving a good education, creating satisfaction with study conditions, study practices, and time devoted to studies. Research conclusions indicate that the inclusive character of the findings should prompt the academic world to examine mobility in higher education from a cultural perspective. Specifically, it is necessary to consider the diversity of practices, study styles, and preferences among international students.
\end{abstract}

Keywords: Cultural Differences; Higher Education; Mobility

\section{INTRODUCTION}

$\mathrm{n}$ the $21^{\text {st }}$ century, following the many technological changes during the previous hundred years, the
world has become "flatter" and more global than ever (Friedman, 2006). Globalization, affecting almost
all aspects of life, has had an impact on higher education as well - it has become pervasive and has reached a previously unprecedented scope (Manikutty, Anuradha, \& Hansen, 2007), accompanied by a fundamental 
transformation of students of higher education. International accreditation accords, ${ }^{1}$ lecturers who move from school to school, accessibility and availability of academic knowledge - all have facilitated mobilization in the academic world. Globalization is not a theoretical concept, rather one that is evident in daily academic life. One of the most prominent manifestations of the mobile world of education is the evident shift in the composition of the student population, reflecting a transition from cultural homogeneity to heterogeneity. These changes transform crosscultural studies from a discipline investigating a relatively marginal occurrence to one devoted to a rapidly accelerating phenomenon, moving from the margins to the center. For example, the number of international students who came to the United States to study multiplied by 2.5 from 1998 to 2004. In the same period, the number of international students in Australia doubled and in England and Germany, their number increased by a factor of 5 or 6 (Schmalzer \& Neubauer, 2007). Currently, international students number over two million and, according to estimates, the number will top eight million by 2025 (Altbach, 2004).

Rising numbers imply a corresponding change in students' cultural composition. This change has been the object of much research, with the goal of tracking the consequences of the relationship between students' cultural context and learning styles (e.g., De Vita, 2001; Jaju, Kwak, \& Zinkhan, 2002; Kainzbauer \& Haghirian, 2005; Keuchel, Neubauer, \& Anuradha, 2007; Paul \& Arcodia, 2002; Ramburuth, 2001). The research literature discusses differences in learning styles and preferences between widely varying study fields and cultures: between white and black students in the United States (Rovai, Gallien, \& Wighting, 2005), Australian and Japanese students of accounting (Auyeung \& Sands, 1996), Japanese and American managers (Yamazaki \& Kayes, 2005), German students and Canadian and American students (Barmeyer, 2004), and others. In all of these studies, students' culture of origin is the major explanatory factor of differences between the groups.

Culture is a type of shared collective baggage carried by group members. It includes various motifs, values, beliefs, identities, and meanings - products of the shared experience of group members - that are passed on from generation to generation (House et al., 2004). Culture, and within it socialization, are the most powerful processes within human society (Hayes \& Allinson, 1988). Some see culture as a type of software (Hofstede, 2001), producing an intrinsic normative model that dictates the conduct of group members. This contention, its deterministic character notwithstanding, has been proven in endless studies - people perceive, experience, and grasp their existence in accordance with the cultural foundation from which they emerged (e.g., Nisbett, 2003).

Each culture has its own norms, values, views, and ethics, and these significantly shape students' learning style and preferences (Jacobson, 1996). The term "learning style" is primarily attributed to Kolb (1984), who proposed a four-level cyclic model of learning, consisting of Concrete Experience, Reflective Observation, Abstract Conceptualization, and Active Experience. He claimed that these styles exist among all healthy adults to varied degrees. One's learning style is relevant not only to formal studies, but also to other aspects of life involving assimilation of new information. According to this definition, learning involves all aspects of human activitythought, reflection, sensation, and action - and over time, one develops certain capabilities and preferences; i.e., a learning style. This style includes emotional, cognitive, and physiological components, and affects the manner in which one perceives, thinks, remembers, and judges various stimuli and situations (Curry, 2000).

Learning style has been found to demonstrate significant dependence on students' initial cultural context. For example, a recent study found that the formal learning model internalized from early school culture has a crucial impact on students' learning patterns at a later age (Yahaya et al., 2010). Joy and Kolb (2009), who compared the learning styles of 533 students of seven different nationalities, found a significant correlation between culture and learning style. Other research findings indicate that students from cultures inclined to intra-group collectivism, institutional collectivism, uncertainty, future orientation, and avoidance, prefer a more abstract learning style. In contrast, students from cultures inclined to inter-collectivism, and uncertainty-avoidance and assertiveness - tend to prefer a reflective learning style.

\footnotetext{
${ }^{1}$ Agreements aimed at mutual recognition of study courses and academic degrees and facilitating standardization and matching of academic study courses and credits for identical degrees across a wide geographical span (see for example the Bologna Accords).
} 
The cultural dimensions selected by the researchers cited above are based on the typology proposed by House et al. (2004), which characterizes cultures on several cultural dimensions; i.e., power distance, gender egalitarianism, humane orientation, uncertainty avoidance, future orientation, institutional collectivism, and in-group collectivism. This categorization has, at its base, the typology proposed by Hofstede (2001) who classified culture into four dimensions: 1) power distance, 2) collectivism versus individualism, 3) uncertainty avoidance, and 4) femininity versus masculinity. Attempts to categorize and characterize differences between cultures stem from awareness of the impact of these social differences on people's lives. The relatively new discipline of "intercultural psychology" is based on precisely this assumption - that we can understand human psyche only by understanding people's original cultural milieu. This approach perceives culture and psyche as one (Shweder, 1991). It gains additional significance when applied to the experience of international students who travel overseas with the goal of realizing their academic ambitions. This transition is often accompanied by "culture shock" (Olaniran, 1996). Entering a new learning environment involves exposure to unfamiliar values, views, and behavior patterns. Although most students succeed in recovering from the shock and becoming acclimatized, differences in style, preferences, and learning practices continue to divide between students from different cultures, with a seemingly immutable relationship between geographical location and learning preferences.

As early as the 1980s, Hofstede (1986), a leading veteran scholar of intercultural studies, explained the connection between learning and culture, as based on the relationship between the type of cognitive development and socialization. He claimed that human cognitive development and cognitive abilities are a product of all the social patterns in one's environment. Barmeyer (2004) confirmed these contentions in his comparison of the learning styles of 353 students from France, Germany, and Quebec. The learning style of each student was determined by means of the Learning Style Inventory (LSI) which maps learning styles according to the theory proposed by Kolb (1976). Research results indicated that German students have a different learning style than French-Canadians and Canadians. The French and the Canadians showed a significant preference for the concrete learning style, while the Germans had more of a preference for the abstract learning style. The author claimed that the preference displayed by the Canadians and the French indicates a learning style that favors personal involvement with people and an intuitive approach to problem-solving. In contrast, Germans tend to favor theoretical stimuli, with stress on logical orientation over a subjective-cognitive orientation.

Aside from the observed effect of culture on learning style, culture was also found to shape and influence student expectations of faculty and of academia, as well as their learning practices (McCargar, 1993; Leung, Ginns, $\&$ Kember, 2008). In addition, differences between cultures were also found in students' administrative expectations of their schools. Students from different cultures differ on three dimensions related to the evaluation of the quality of services: 1) faculty willingness to help students develop academic skills, 2) sympathy and encouragement by the faculty, and 3) faculty knowledge and proficiency regarding academic requirements and programs. Comparing American to Australian students, the latter were found to have higher expectations on all dimensions.

Differences between students are evident in learning practices as well, and a consistent variance may be indicated in the transition between cultures (Richardson, 1994). Richardson claims that it is possible to characterize approaches to higher education, in general, as "deep" versus "surface". A deep approach is one that espouses learning as aimed at understanding meaning, while the surface approach identifies learning with duplication of study material. For example, Austrian students were found to have a deep approach and tend to internalize study material. The contention is that students' learning practices are strongly related to the learning approach they embrace.

Aside from the effect of culture on features of academic studies, the research literature indicates that demographic variables interact with cultural context. For example, field of specialty, sex, age, and schooling were found to interact with culture and learning style (Kolb \& Kolb, 2005). Research investigating demographic variables and culture found that they have a modifying effect that cancels out differences. Zualkernan, Allert, and Qadah (2006) compared the learning style of Middle East engineering students to that of US engineering students. The researchers state that despite the many differences between cultures, there is a great deal of similarity between the learning styles of the two groups. This study included all the demographic variables presented above. In contrast, Yamazaki (2005) controlled for the variance in demographic variables, with culture as an independent variable. He found different learning styles and capabilities in different cultures. 
In the current study, we sought to examine whether and to what degree cultural context influences the learning style, expectations, and practices of Israeli versus CIS students. As a country that absorbed over one million immigrants from the former Soviet Union between 1989 and 2009, Israel has a particular interest in studying the role of culture in higher education. At present, immigrants from the former Soviet Union comprise about one-fifth of all Jews living in Israel and 13 percent of all citizens of Israel (e.g., Davidovitch, Sinuany-Stern, \& Soen, 2009). The study consisted of 1,122 students, 554 studying in schools of higher education in Jerusalem and Ariel (Israel) and 568 in Ekaterinberg (Russia). The questionnaire was developed specifically for this study and included 44 items related to four main dimensions: 1) students' personal and academic background characteristics, 2) perception of the academic world and of the opportunities offered by higher education, 3) evaluation of the study environment, and 4) faculty/student responsibility for the study process.

\section{FINDINGS}

\section{Data on Personal and Family Background of Israeli and CIS Students}

Significant correlations were found between country of origin and the following variables: age group, gender, economic status of student's family of origin, high school graduation achievements, previous work experience, and student's field of study.

Interestingly, in both countries, students with high academic achievements in high school perceive academic studies as preparation for future work in the field studied (higher by a factor of 1.45), particularly those who graduated from high school shortly before beginning their academic studies. The longer the interval between high school graduation and commencing academic studies, the lower the probability (by a factor of 0.88) of perceiving academic studies as preparation for one's professional life. Moreover, CIS students do not perceive their academic studies as an opportunity to increase their chances of advancing in their career (lower by a factor of 0.65) compared to Israeli students. Students' age contributes to this perception; every additional year in age increases the probability by a factor of 1.05 . The number of years since high school graduation contributes to the perception that academic studies afford learners the chance to become scholars/intellectuals. Every additional year increases the probability of this perception by a factor of 1.03 .

CIS students perceive academic studies as a social opportunity to meet new people (higher by a factor of 7.21) compared to Israeli students; yet, the higher students' academic achievements, the lower the probability (by a factor of 0.64) that they will perceive the academic world as a social opportunity. In contrast, CIS students do not perceive academic studies as an opportunity to develop personal skills and qualities (lower by a factor of 0.37) compared to Israeli students.

Students were asked to specify up to three considerations that are most important in selecting an institution of higher education. Differences were found in students' considerations. Israeli students attribute greater importance to compatibility between students' grades and school requirements (55.2\% versus $30.1 \%$ ), ease of access (25.8\% versus $13.3 \%$ ), low tuition (17.9\% versus $10.6 \%$ ), and friends who attended the school (12\% versus $7.8 \%$ ). CIS students attribute greater importance to schools that offer interesting professions (70.3\% versus $36.3 \%)$, the school provides a good education $(46.5 \%$ versus $36.8 \%$ ), graduates of this school are in high demand in the labor market ( $26.9 \%$ versus $8.4 \%)$, the school is prestigious (18.4\% versus $7.6 \%)$, and the dorms are good (5.8\% versus $1.1 \%)$.

Students stated up to three of most important elements they used when evaluating studies at their current school. Israeli students attribute greater importance to lecturers and teaching assistants (45.7\% versus $34.5 \%$ ), active student life (11.1\% versus 6.9\%), and school expenses (10.2\% versus 6.1\%). CIS students attribute greater importance to relationships between the students (39.7\% versus $31.6 \%$ ), guarantee of employment upon graduation (28.9\% versus $12.8 \%)$, advanced teaching methods (16.8\% versus $11.8 \%)$, studies are not hard $(15.1 \%$ versus $10.3 \%)$, and the prospect of being proud of my school (16.9\% versus $7.1 \%)$.

Students noted up to three of the most interesting elements of their studies. The most interesting elements of academic studies are practical courses (47.6\%), lectures (46.3\%), and practical training and working in a certain organization (36.6\%). The least interesting elements of academic studies are scientific conferences (8.2\%), taking 
part in scientific research (8.6\%), and developing my own projects (13.3\%). Israeli students are more interested in exams and grades $(29.6 \%$ versus $9 \%)$ and in independent work using varied information sources (18\% versus $13.4 \%$ ). CIS students are more interested in practical courses (56.6\% versus $38.3 \%)$, seminars $(39.1 \%$ versus $2.4 \%)$, and scientific conferences (14.5\% versus $2.6 \%)$.

Students noted the considerations that determine their choice of elective courses. The main consideration determining choice of elective courses is interest in the course (71.6\%). The least important consideration is the goal of acquiring a higher education with as little effort as possible (8.8\%). Considerations valued by Israeli students are the opinion of students who took the course (38.3\% versus $13.2 \%$ ) and the goal of acquiring a higher education with as little effort as possible (14.8\% versus 3.3\%). The consideration valued by CIS students is the desire to know more about the field they chose $(44.1 \%$ versus $30.7 \%)$.

Students noted up to five characteristics of proficient and competent lecturers. The feature most characteristic of proficient and competent lecturers is one who explains everything clearly and in a detailed manner (85.7\%). Other characteristics of proficient and competent lecturers are ability to understand students (59.5\%) and practical experience in the field $(48.1 \%)$. The least characteristic features of proficient and competent lecturers are giving additional home assignments (8\%) and engaging in scientific research (11.4\%). Israeli students awarded higher ratings to practical experience in the field (53.5\% versus $42.9 \%)$, taking time to clarify practical aspects of applying study material (36.8\% versus $30.4 \%$ ), having an advanced academic degree (25.4\% versus $19.8 \%$ ), not giving failing or low grades (20.8\% versus $9.4 \%)$, offering to work with students on a one-on-one basis $(19.7 \%$ versus $10 \%$ ), and giving additional home assignments (11\% versus 5\%). CIS students awarded higher ratings to lecturers who are able to understand students (68.1\% versus $50.6 \%)$, are capable of presenting themselves well (44.8\% versus $30.9 \%$ ), emphasize controversial issues ( $40.2 \%$ versus $26.7 \%$ ), work personally, help and advise students after school hours (36.1\% versus $30 \%)$, maintain discipline $(25.4 \%$ versus $17.1 \%)$, constantly use varied technologies (21.7\% versus $12.9 \%)$, and engage in scientific research (14.2\% versus $8.5 \%)$.

Students noted up to two answers to the question, what is required of them in order to receive a good education. The most common answers were: Students who wish to receive a good education must simply choose the right field $(51.3 \%)$, devote most of their time to their studies (42.9\%), and constantly display initiative during their studies $(41.5 \%)$. Other responses included, it is less necessary to form useful connections with the right people (15.9\%). Israeli students tend to think that in order to get a good education, it is simply necessary to follow all instructions of lecturers and teaching assistants ( $32.7 \%$ versus $12.1 \%$ ), while CIS students tend to think that in order to receive a good education, it is simply necessary to choose the right field (57.3\% versus $44.9 \%)$ and constantly display initiative during your studies $(50.4 \%$ versus $32.1 \%)$.

Students ranked their satisfaction with various study conditions on a scale of 1 to 3 (very dissatisfied, occasionally satisfied, and very satisfied). Study conditions with which students are more satisfied include access to information (2.37), study halls and classrooms equipped with technological learning aids (2.36), and clean and spacious study halls and classrooms (2.33). They are least satisfied with financial aid, incentives, scholarships (1.96), living conditions in the dorms (2.06), and tuition (2.06). Israeli students are more satisfied with printing, photocopy and scanning options (2.34 versus 2.23 ), class schedules (2.28 versus 2.19$)$, and internet access (2.26 versus 2.16). CIS students are more satisfied with access to information (2.41 versus 2.31 ), food in the dining room and cafeterias (2.30 versus 2.10$)$, tuition (2.23 versus 1.89$)$, living conditions in the dorms (2.14 versus 1.98$)$, and financial aid, incentives, and scholarships (2.10 versus 1.80$)$.

Students were asked to state their preferences regarding courses. Findings showed that:

- $\quad 84.2 \%$ of Israeli students, versus $63.5 \%$ of CIS students, would like lecturers to provide students with lecture text in advance.

- $\quad 63.3 \%$ of Israeli students, versus $53.9 \%$ of CIS students, are interested in studying at another school in the country as part of a student exchange program.

- $\quad 71.5 \%$ of CIS students, versus $53.3 \%$ of Israeli students, expressed interest in studying in another country as part of a student exchange program.

- $\quad 53.3 \%$ of Israeli students often discuss lecture issues with friends, versus only $37 \%$ of CIS students.

(C) 2012 The Clute Institute http://www.cluteinstitute.com/ 
- $\quad 25.7 \%$ of CIS students prefer oral exams, versus $6.5 \%$ of Israelis; $41.3 \%$ of Israeli students prefer multichoice exams, versus $36.4 \%$ of CIS students; $42.6 \%$ of Israeli students prefer an exam combining open- and closed-ended questions, versus $18.3 \%$ of students from the CIS; $19.6 \%$ of students from the CIS prefer written exams with open-ended questions, versus $9.6 \%$ of Israeli students.

- $\quad 68.1 \%$ of CIS students work on professional literature at least 2 to 3 times a week, versus $38.5 \%$ of Israeli students.

Finally, students ranked various issues related to their studies on a scale from 1 to 10 . Findings showed that:

- $\quad$ CIS students have a higher evaluation of issues related to the subject studied than Israelis - content and manner of material presentation, provision of professional literature, and use of advanced technological means.

- $\quad$ Israeli students spend more hours a day at school (7.65) versus CIS students (6.10).

- Israeli students prefer a higher ratio between theoretical and practical courses (54.33\%) than do CIS students $(46.41 \%)$.

\section{DISCUSSION AND CONCLUSION}

In the current study, we examined the impact of cultures of teaching and learning at schools of higher education in different countries. Studies held to date reported that socialization is a powerful factor (Hayes \& Allinson, 1988) affecting individuals' cognition and, consequently, their sensory perception of reality (Nisbett, 2003). Understanding the impact of culture on one's life is relevant today more than in any other era in human history. In the $21^{\text {st }}$ century - the global century-the academic world and its residents have become mobile. Students, lecturers, and knowledge are moving across the globe and rendering it "flat" (Friedman, 2006).

This constant oscillation, although infusing in us a sense of the "academic global village", does not eliminate intercultural differences. The current findings indicate that although we would like to think of the academic world in terms of a "village," a place in which we are all members of the global culture, this is absolutely untrue. Even in a time when technology has succeeded in "erasing" geographical borders, the cultural significance of the nation-state may be said to have retained its centrality. This claim is confirmed by the fact that we found significant differences on almost all dimensions on which the cultures were compared. We may even speak of two fairly different profiles of students in the two countries.

Regarding the personal and academic features of CIS students, these are young people under $21(98.4 \%)$ mostly female (70.8\%) who study at faculties of health sciences $(51.5 \%)$ and faculties of social sciences and the humanities (31.2\%), with no work experience, who perceive the academic world as a professional springboard. In contrast, Israeli students are mostly over 24 (58\%) - with a similar ratio of females/males - studying at faculties of social sciences and the humanities (57.9\%), and with some work experience (62.3\%), who see their future in the field studied $(48.9 \%)$.

Differences in background features of learners are linked, among other things, to military service, which is compulsory in Israel but not in the CIS. Every Israeli citizen over 18 is required to enlist; men are required to serve three years and women two years. Thus, Israeli students, as a rule, are older than CIS students. The research literature indicates that demographic differences interact strongly with culture and with features of learning and learners (Yamazaki, 2005; Kolb \& Kolb, 2005). This claim is manifested in the differences between countries in perceived opportunities afforded by academic studies. CIS students (who are younger) - much more than Israelis perceive their studies as an opportunity to have a good time and meet new people. Age serves as an explanatory variable here, as at different ages people have different motivations and goals in life. Israelis, in contrast, perceive their studies mainly as a means of developing skills, personal qualities, and a career.

These differences between cultures are interwoven throughout the findings: 
- $\quad$ in perceived important factors for selecting a school (CIS select schools based on interest; Israelis select schools based on admission requirements)

- $\quad$ in important factors for evaluating the school (CIS - relationships between students; Israelis - lecturers and teaching assistants)

- $\quad$ in causes of interest in studies (CIS - practical courses; Israelis - exams and grades)

- $\quad$ in important factors for students' perceptions of lecturers as proficient (CIS - lecturers who are able to understand the student; Israelis - lecturers who have practical experience in the field)

- $\quad$ in requirements for receiving a good education (CIS - selecting the correct field and demonstrating initiative; Israelis - following all instructions of lecturers and assistants)

- $\quad$ in grounds for satisfaction with study conditions (CIS - technological equipment; Israelis - physical facilities)

- $\quad$ in learning practices (CIS - working with professional literature; Israelis - study material is provided in advance by the lecturer)

- $\quad$ in time devoted to study (CIS students see this as more important than Israelis)

The conspicuous differences between countries reflect a complex state of affairs. On the one hand, we are witnessing the blurring of geographical borders and, on the other hand, geography, and thus culture, retain a crucial role in shaping students' expectations, practices, and preferences in regard to their studies. These findings, which take into account the demographic element, show that there is a causal connection between the demographic setting, together with the cultural setting, and the field of higher education. This finding is incompatible with studies that argue that demographic variables weaken the effect of culture (Zualkernan et al., 2006). In our opinion, the inclusive character of the findings should motivate the academia to study mobility within the world of higher education from a cultural perspective, and consider diverse study practices, styles, and preferences of international students. From an operational perspective, this requires training teachers and preparing students for the new cultural world they are encountering, with both sides attempting to draw closer to each other. In our opinion, there is room to assume that such cross-cultural training might help lecturers with their teaching, ease the absorption of students, and improve student performance.

\section{AUTHOR INFORMATION}

Nitza Davidovitch is the director of the Department of Academic Development and Assessment and a lecturer in the Department of Behavioral Sciences in Ariel University Center of Samaria. She was born in Israel, and received her Ph.D. in Education in Bar Ilan University, Israel. Areas of interest: Assessment and Evaluation in Higher Education, Teaching improvement in the academe, Holocaust and Jewish identity, cultivating the cultural history of Jewish sects, and moral education. E-mail: d.nitza@ariel.ac.il. Corresponding author.

Dr. Lobova Elena is a director of the Center of Sociological Researches and a lecturer in the Department of Social Sciences in the Ural State Pedagogical University (Ekaterinburg, Russia). She was born in Russia, received her Ph.D. (candidate of Social Sciences in Russia) in the Ural State University in 2006. Areas of interest: Professional self-determination of the youth; Estimation of quality of education; Visual sociology. Contact information: Department of Sociology, Ural State Pedagogical University, Tel. 7-343- 2573616, fax. 7-343- 2573480, E-mail: Elobova@yandex.ru

Pryamikova Elena is the senior lecturer of chair of sociology in Ural State Pedagogical University (Ekaterinburg, Russia). She has received PhD (degree of the candidate of social sciences) in 2004. Areas of interest include: Research of city space; Individual and society, Social competence; Changes of educational space under conditions of the information society. Contact information: Department of Sociology, Ural State Pedagogical University, Tel. 7-343- 3361461, fax. 7-343- 2573480, E-mail: Pryamikova@yandex.ru

Semenova Tatyana is a student of first-year graduate of the Department of Social Sciences in the Ural State Pedagogical University (Ekaterinburg, Russia). Tatyana is a specialist of a center of quality management in education in USPU. She was born in Russia, received BA in sociology in Ural State Pedagogical University (Russia, 
Yekaterinburg). Areas of interest: The quality of education; Problems of student motivation in education; Quality activities of students. Contact information: Tel. 895020422 79, E-mail: taniasemen@inbox.ru

Pechenkina Tatiana is graduate of the Department of Social Sciences of the Ural State Pedagogical University (Ekaterinburg, Russia). She has received MA in Social Sciences in 2011. Now she is an analyst in a center of marketing and social researches "Socium". Areas of interest include: Verbal behavior, language researches, Investigation of gender-specific verbal behavior of teachers; Problems of reliability methods in the study of children's audience. Contact information: Tel. 73433712265 (additional 103), Mob. tel. 79222963 476, E-mail: tatpechenkina@gmail.com

Yachmenyova Maria is a post-graduate student of the Ural State Pedagogical University, chair of theoretical and applied sociology. In 2010 has received MA in Social and Economic Sciences. Areas of interests include: Educational sociology, Sociology of person, Problems of the general and vocational training in Russia, Development of social competence of pupils and students. Contact information: Tel. 7-963-447-93-13, E-mail: obscure2003@yandex.ru

\section{REFERENCES}

1. $\quad$ Altbach, P. G. (2004). Higher education crosses borders. Change, 36(2), 18-24.

2. Auyeung, P., \& Sands, J. (1996). A cross cultural study of the learning style of accounting students. Accounting and Finance, 36, 261-274.

3. Barmeyer, C. (2004). Learning styles and their impact on cross-cultural training: An international comparison in France, Germany and Quebec, International Journal of Intercultural Relations. 2, 577-59.

4. Curry, L. (2000). Review of learning style, studying approach, and instructional preference research in medical education. In R. J. Riding, \& S. G. Rayner (Eds.), International perspectives on individual differences: Vol. 4. Cognitive styles. Stamford, CT: Ablex Publishing.

5. Davidovitch, N., Sinuany-Stern, Z., \& Soen, D. (2009). The story of scientists' immigration and integration in the academe 1989-2009. Tel Aviv: Alpha Publishing, ISSN: 978-965-7376-22-5. (in Hebrew).

6. De Vita, G. (2001) Learning styles, culture and inclusive instruction in the multicultural classroom: a business and management perspective. Innovations in Education and Teaching International, 38, 165-173.

7. Friedman, T. L. (2006) The world is flat: A brief history of the twenty-first century. NY: Farrar Straus and Giroux.

8. Hayes, J., \& Allinson, C. W. (1988). Cultural differences in the learning styles of managers. Management International Review, 28, 75-80.

9. Hofstede, G. (1986). Cultural differences in teaching and learning. International Journal of Intercultural Relations, 10, 301-320.

10. House, R. J., Henges, P. J., Javidan, M., Dorfman, P. W. \& Gupta, V. (2004). Culture, leadership and organizations: The GLOBE study of 62 Societies. Journal of World Business, 37(1), 3-10.

11. Jacobson, W. (1996). Learning, culture, and learning culture. Adult Education Quarterly, 47, 115-128.

12. Jaju, A., Kwak, H., \& Zinkhan, G.M. (2002) Learning styles of undergraduate business students: a cross cultural comparison between US, India and Korea, Marketing Education Review, 12, 49-60.

13. Kainzbauer, A., \& Haghirian, P. (2005) Teaching across cultures: European teaching experience in Asian business classrooms. Paper presented in the Proceedings of the First International Conference on Intercultural Communication Competence: Implications for Business, Education and Politics, Singapore. CD ISBN 981-05-4450-2.

14. Keuchel, S., Neubauer, M., \& Anuradha, N. S. (Eds.) (2007) Cross cultural approaches to learning and studying: A comparative study on Austria, Germany, and India. New Delhi, India: MacMillan.

15. Kolb, D. A. (1984) Experiential learning: Experience as the source of learning and development. Englewood Cliffs, NJ: Prentice Hall.

16. Joy, S. \& Kolb, D. A. (2009). Are there cultural differences in learning style? International Journal of Intercultural Relations, 33, 69-85.

17. Kolb, A. Y., \& Kolb D. A. (2005). The Kolb learning style inventory-version 3.12005 Technical specifications. Boston: Hay Group Transforming Learning. 
18. Leung, D. P., Ginns, P., \& Kember, D. (2008). Examining the cultural specificity of approaches to learning in universities in Hong Kong and Sydney. Journal of Cross-Cultural Psychology, 39, 251-266

19. Manikutty, S., Anuradha, N. S., \& Hansen, K. (2007). Does culture influence learning styles in higher education? International Journal of Learning and Change, 2, 70-87.

20. McCargar, D. F. (1993). Teacher and student role expectations: Cross-cultural differences and implications. Modern Language Journal, 77, 192-207.

21. Nisbett, R.E.(2003). The geography of thought: How Asians and Westerners think differently...and why. The Free Press, New York.

22. Olaniran, B. A. (1996). Social skills acquisition: A closer look at foreign students on college campuses and factor influencing their level of social difficulty in social situations. Communication Studies, 47, $72-88$.

23. Paul, B., \& Arcodia, C. (2002) Linking learning style preferences and ethnicity: international students studying hospitality and tourism management in Australia. Journal of Hospitality, Leisure, Sport and Tourism Education, 1, 15-27.

24. Ramburuth, P. (2001). The internationalisation of education: Implications for student learning and sociocultural adjustment. Developing Global Capacity Through International Education. $15^{\text {th }}$ Australian International Education Conference. Sydney.

25. Richardson, J. E. (1994). Cultural specificity of approaches to studying in higher education: A literature survey, Higher Education, 27, 449-469.

26. Rovai, A. P., Gallien Jr., L. B., \& Wighting, M. J. (2005). Cultural and interpersonal factors affecting African American academic performance in higher education: A review and synthesis of the research literature. Journal of Negro Education, 74(4), 359-370.

27. Schmalzer, T., \& Neubauer, M. (2007) Learning and studying across cultures. In T. Schmalzer, G. Apfelthaler, K. Hansen, \& R. Singh (Eds), Intercultural communication competence: Implications for learning and teaching in a globalized world. New Delhi, India: Macmillan.

28. Shweder, R. (1991). Thinking through cultures. Cambrudge, MA: Harvard University Press.

29. Yahaya Y., Mukhtar, M., Nielsen, D. N., \& Zakaria, M. S. (2010). Establishing T-shape graduates: Delivering curriculum using a union approach based on service orientation. The 2nd International Research Symposium in Service Management Yogyakarta, Indonesia. July 26-30, 2011.

30. Yamazaki, Y. (2005). Learning styles and typologies of cultural differences: A theoretical and empirical comparison, International Journal of Inter-Cultural Relations 29, 521-548.

31. Yamazaki, Y., \& Kayes, D. C. (2005). Expatriate learning: Exploring how Japanese managers adapt in the United States. Paper presented at the annual meeting of the Academy of Management, Honolulu, Hawaii.

32. Zualkernan, I. A., Allert, J., \& Qadah, G. Z. (2006). Learning styles of computer programming students: A Middle Eastern and American comparison, IEEE Transactions on Education. 49, 443-450. 
NOTES 